\title{
Corruption in Natural Disaster Aid: The 2004 Indonesian Tsunami
}

Nicole Brooks, Karin Klau, Joseph Orr \& Chris Stanford

\section{Background}

The tsunami that affected Asia and African countries in December 2004 was one of the most destructive natural disasters in recent times. Aceh alone suffered an estimated 167,000 deaths and 566,000 displaced persons (USAID, 2005). The response by donor countries and individuals was swift and unprecedented in magnitude, however, after more than one year, thousands of families remained effected by corruption and were forced to huddle in tents instead of living in permanent housing (TI, 2010). Review studies such as Mitchell (2010), show that the outcomes achieved through the aid response were inefficient and inequitable.

Natural disasters, especially when they occur in developing countries, strain government budgets significantly. With large populations (among donors or beneficiaries) believing provisional aid is substantial when in reality it is small (Mitchell, 2010), powers amongst NGO lobbyists growing, and the media's willingness and ability to distribute damaging stories about corrupt aid practices (Oxfam, 2010), it is easy to see why national governments, eager to appease electorates (presuming they are democratic of course) and the international community, are motivated to provide effective natural disaster aid. In this context, giving aid to countries plagued with corruption poses a difficult dilemma. This paper highlights market failures in natural disaster aid using the case of Aceh, and recommends a strategy that adjusts government agents' incentives to take a path that could arguably assuage the problem of corruption by reducing the severity of the moral hazard problem in an afflicted government. 


\section{Market Description}

A natural disaster creates an immediate and more inelastic demand for primary needs among its victims. However, due to the disruption of market mechanisms, excess demand for necessities, and the destruction of some factors of production such as land, labour and capital, buyers often suffer reduced affordability and sellers typically face the problem of an inability to supply. Consequently, this shortfall in domestic markets for such necessities as food, shelter, water and medical supplies are targeted by humanitarian aid, while the restoration and improvement of the factors of production and the infrastructure are funded through development aid. Natural disaster aid can therefore be viewed as a combination of humanitarian aid and development aid.

In order to characterize this market for disaster aid we could label the donors as the suppliers of natural disaster aid. These would include non-profit organisations, governments, private business and individuals. Similarly the consumers of natural disaster aid are those affected by the disaster.

Interestingly though, in a natural disaster situation, many factors such as communication breakdown and in-ability to meet exchange partners aggravate the difficulty of these suppliers and consumers engaging in market transactions. For example, when the infrastructure has been severely impacted, the willingness to supply aid is not enough to get it to its potential consumers. Also, suppliers are often international NGOs or foreign governments who must engage with domestic governments before they can access the affected consumers, which introduces a number of political economy concerns.

Following the tsunami, governments across the world (or various countries) played a critical role, dispatching significant portions of their stockpiled humanitarian goods and services to Aceh. Australia, too, had a large involvement, committing $\$ 1$ billion in aid to Indonesia (Burford, 2005). The aggregate quantities of humanitarian goods supplied highlight the benefits of government intervention in what could be considered a public 
good and would naturally be underfunded if left to its own accord due to the free rider problem.

The market of humanitarian aid following a natural disaster could be viewed as monopolistic competition, because there are a large number of suppliers all providing only slightly differentiated range of limited basic goods and services. Differentiation could also be on the basis of the donor's strategic location or history of foreign direct investment (FDI) in the recipient country, thus some donor countries may have a comparative advantage in supplying aid. Donor governments are also more likely to support and provide aid for other reasons such as maintaining trade links, engaging in a quid pro quo political game in the international community, relieving internal pressure from an electorate to show support for the impacted country, and so on.

However, often there are certain strings attached to the provision of aid, countries donating on the condition that the aid is used in a certain way. This type of situation creates a market that is more oligopolistic, because aid is supplied on the proviso for instance that reconstruction contracts are awarded only to the donor country's firms rather than to those from rival countries, or that only the donor country's goods and services are used. A quid pro quo scenario emerges in a situation of simultaneous strategic interaction with other donor countries and the recipient country. This creates a limited number of powerful suppliers, who, without trade practice acts, can enter collusive agreements forcing the price level higher. There was evidence of this in Aceh, where local construction groups won inflated contracts through strategic alliances (TI 2010). With high levels of corruption in Indonesia, it is reasonable to suggest that political rent-seeking from powerful local firms had a major impact on the decisions of local politicians in awarding contracts for goods and services for reconstruction. 


\section{Market Failure and Externalities}

The outcomes of markets are usually assessed on the grounds of their efficiency and fairness. In the case of Aceh, according to victim surveys the natural disaster aid market failed to deliver aid efficiently or fairly (Mitchell 2010).

Aid can only be as effective as the political institutions in a country that deploy it. For every dollar of aid, a portion is taken by the recipient government reducing the real value of a donated dollar below its face value. Some of this loss may be necessary to enable the transmission of the donated dollar. However, the fact remains that the more a recipient government wastes in socially unproductive ways such political rent, or corruption, the less there is for the population affected by a natural disaster, reducing the consumer surplus and creating an inefficient natural disaster aid market. The more the political institutions of the recipient country are poorly managed, corrupt, or apathetic the more likely this situation would be exacerbated. Five years following the tsunami, Indonesia still ranked 111 out of 180 countries in the 2009 version of Transparency International's Corruption Perceptions Index, meaning it is still perceived as having significant corruption within its civil service and political system.

In such a case, aid can be seen as simply a wealth transfer that may only serve to entrench the recipient country's political inefficiency, and give the donor countries a false sense of altruism.

Market inefficiency can also arise from overregulation or 'red tape'. In this scenario, demand is high, supply of aid from donor countries is available, but bureaucracy delays the process of transferring the supply of goods and services to the consumers who demand it. Evidently, the excessively large queue dissipates surplus, this leads to deadweight loss in the market, and a large reduction in both consumer and producer surplus. Following the tsunami, the Indonesian government was suspicious of foreign assistance so it increased its regulation of foreign companies, and was quick to re-establish its own full control of logistics and funding for the redevelopment plan. 
Even though demand is created by victims, they do not pay for aid. Construction companies for example are businesses that win contracts from the government, which is a case of business functioning as the buyer of natural disaster aid in exchange for the services rendered. Aid funds flow from the aid agencies such as the UN and other nonprofit organisations such as Oxfam International to local business vendors, whom secure aid in exchange for providing goods and services. Therefore, in the ideal state, the victims, with-out payment, receive the benefits of aid due to the agency-business transaction.

Negative externalities in donor aid also occur. In a country as large and populous as Indonesia, using local labour, supplies and infrastructure enabled Indonesian firms to have a comparative advantage over foreign countries and their contractors. However, in Aceh, there were documented cases of protectionism (over-regulation), fraud, bribery, kick backs and a general mismanagement of funds, which inflated prices beyond 20 to 30 percent (Schultz \& Søreide 2006), all of which reduced consumer surplus.

A negative externality of foreign aid is known as a donor country's moral hazard encapsulated in Buchanan's Active Samaritan - Passive Samaritan Dilemma (Raschky and Schwindt 2009). Comparing pay-offs between donor and recipient countries in the Active Samaritan Dilemma, Nash Equilibrium is achieved when the recipient offers a low level of effort, since the donor is always constrained to help - a fact that the recipient takes for granted and acts accordingly. In the Passive Dilemma, the donor contributes less when the recipient's efforts are high, so again the recipient chooses a low effort. The dilemma of the Samaritan is that they always get exploited (Raschky and Schwindt, 2009). Its "Moral Hazard" is that it can never commit to not helping, even though that is not its dominant strategy. Aid exacerbates the moral hazard problem for the donor country because the recipient (the government of the victims) counts on foreign aid from the donor, which allows poor political and economic management to linger. This ultimately impacts on the welfare and longer term development outcomes of the recipient country. 


\section{Intervention design and rationality}

Corruption looms large when a natural disaster strikes because there is a need to be seen as acting quickly. Often regulations covering bureaucratic behaviour are relaxed in the name of expediency, reducing the likelihood of being caught in an ex-post investigation. Other factors that influence the corruption of a rational agent are the ability to influence decisions and the size of the potential rewards (Schultz \& Søreide, 2006).

An intervention to mitigate corruption in the provision of donor aid following a natural disaster could involve reducing the incentives to create political rent-seeking, and create a more competitive market between local and donor producers. This paper proposes an intervention that would require that the number of contracts awarded in the reconstruction phase be reduced but their size be increased, while producers from the recipient and donor countries are put 'head to head'. To be awarded the contracts, as decided and regulated by donor country governments, local producers would have to match the contracts of producers from donor countries. In this way, all local producers are encouraged to reduce costly corruption or risk losing the contract. Pitting local suppliers against one another in a setting of local chaos culminates in increased uncertainty of information between the local producers. Local uncertainty of information in conjunction with the once-off nature of the contracts increases the incentives for local suppliers already in a collusive agreement to cheat one another, which has the end result of forming a more competitive market less ailed by corruption.

Focus must also be maintained on donor country suppliers. Donor country suppliers, although better able to collude due to communication and business processes still intact, still face the associated risk of being cheated by both donor and afflicted countries alike. This risk is exacerbated when the contracts are of the one-shot nature. Both donor country projects and local projects should be audited by experienced external auditors well-versed in corruption elimination practices, to ensure product and service homogeneity, quality and performance. External auditors should be given veto powers to both stop and reallocate either local or donor contracts depending on project progression. External 
auditors would be highly compensated to reduce the likelihood of being corrupted, however, would face regular turn-over so that collusive relationships could not be established by the individual. Avenues for whistle blowing should be encouraged. Incentives of local suppliers would change with these measures; however, the long term result would be gains in producer surplus through the gradual mitigation of corruption.

Achieving this outcome would require a take it or leave it approach. If, perhaps through a global institution, all aid was administered by a single entity, take it or leave it could prevail. Donor aid organisations could use their market power to internally generate the incentive to eliminate malpractice thus reducing the moral hazard problem. These measures would require funding, most likely taken from the donated aid itself. Justification would be the trade-off between this funding and the cost of corruption. However, there is also always a risk that intervention can lead to regulatory failure, a case for further investigation.

The tsunami in Aceh highlighted the market inefficiencies and negative externalities inherent in natural disaster aid. Corruption within the recipient government exacerbates the inefficiencies, inequalities and the moral hazard problem. Our proposed intervention for disaster aid aims to limit corrupt practices, leading to a more efficient and equitable market for foreign aid.

\section{References}

- Burford, S (2005) “The prawn behind the stone", Social Alternatives, Volume 24, Issue 3, pp. 22-27

- Jayasuriya, S and McCawley, P (2008) “Reconstruction after a Major Disaster", Asian Development Bank Institute Working Paper, retrieved 05 May 2010, <www.adbi.org/workingpaper/2008/12/15/2766.reconstruction.post.tsunami.experience>

- Mitchell, J, 2010, State of the humanitarian system report, ALNAP, retrieved 17 May 2010, <www.alnap.org/forum/post/60.aspx> 
- Oxfam (2010) "Recognising success and tackling failure", $21^{\text {st }}$ Century Aid, Oxfam International, retrieved 17 May 2010, <www.reliefweb.com>

- Raschky, P and Schwindt, M (2009) “Aid, natural disasters and the Samaritan's dilemma", Policy research working paper 4952, The World Bank Global Facility for Disaster Reduction and Recovery Unit

- Schultz, J and Søreide, T (2006) "Corruption in emergency procurement”, CHR. Michelsen Institute, retrieved 17 May 2010, <www.reliefweb.com>

- TI (2010) "Preventing Corruption in Humanitarian Operations", Transparency International, retrieved 17 May 2010, <www.reliefweb.com>

- USAID (2005) Indian Ocean-Earthquakes and Tsunamis, USAID 